\title{
Severe imbalance of cell proliferation and apoptosis in the left colon and in the rectosigmoid tract in subjects with a history of large adenomas
} M Anti, A Armuzzi, S Morini, E Iascone, G Pignataro, C Coco, R Lorenzetti, M Paolucci,
M Covino, A Gasbarrini, FM Vecchio, G Gasbarrini

\begin{abstract}
Background-Alterations in epithelial proliferation and apoptosis in colonic mucosa are associated with an increased risk of colon cancer. It is unclear if these alterations represent a generalised "field defect".
\end{abstract}

Aims-To analyse segmental patterns of cell proliferation and apoptosis in the colon of subjects with a high and no apparent risk of colon cancer.

Methods-Pancolonoscopy was performed in 15 patients with resected adenomas $(\geqslant 1.5 \mathrm{~cm})$ and in nine subjects without an apparent risk of colorectal cancer. Mucosal biopsies were taken from the right colon, left colon, and sigmoid rectum. Crypt cell proliferation and apoptosis were evaluated, respectively, with bromodeoxyuridine immunohistochemistry and terminal deoxyuridine nucleotidyl nick end labelling of DNA strand breaks. Results are expressed as total labelling index (TLI) and labelling index (LI) for each of the five compartments in which colonic crypts were divided (fourth and fifth compartments were evaluated together) for cell proliferation and as apoptotic index (AI) for apoptosis assessment. Results-No significant segmental variations in proliferation were found in either group. Compared with controls, adenoma patients had higher TLIs for the right $(p>0.05)$, left $(p<0.005)$, and sigmoid rectum $(p<0.05)$ segments, and higher left colon LIs for crypt compartments (compartment 1, p<0.01; compartment 2, p $<0.005$; compartment $3, \mathbf{p}<0.001$; compartments $4-5, p<0.01)$. Control AIs were similar in all segments but in the adenoma patients left colon and sigmoid rectum AIs were lower than their right colon indexes $(p<0.05, p<0.05)$ and corresponding values for controls $(p<0.01, p<0.05)$.

Conclusions-The colonic mucosa of patients with past adenomas presents diffuse hyperproliferation and, distally, abnormally distributed proliferating cells and markedly reduced apoptosis. These changes represent a significant risk for malignancies and could account for the high prevalence of left colon tumours. (Gut 2001;48:238-246)

Keywords: cell proliferation; apoptosis; colon cancer risk
Progression from normal colonic epithelium to cancer involves an accumulation of genetic alterations that gradually leads to the development of a series of phenotypic stages with different biological characteristics and morphological aspects. ${ }^{1}$ One of the earliest events in the carcinogenetic cascade of colorectal cancer is deregulation of cell proliferation within the colorectal glands. ${ }^{2}$ Hyperproliferation and abnormal distribution of replicating cells along the length of the colonic crypts have been described in the apparently normal mucosa of subjects prone to develop colon cancer, such as those with sporadic adenomas. ${ }^{3-8}$

However, cell renewal in these glands involves not only proliferation but also cell loss. The physiological mechanism of cell loss is represented by apoptosis, which is programmed cell death regulated by a complex network of genetic signals. In equilibrium with cell replication, apoptosis contributes to the maintenance of normal tissue homeostasis. ${ }^{9-15}$

Altered rates of epithelial cell apoptosis are believed to play an important role in colorectal carcinogenesis. Progressive inhibition of apoptosis has been described during the transformation of colorectal epithelium to carcinoma. ${ }^{16-18} \mathrm{Ex}-$ pression of the p53 gene and those of the bcl-2 family (the best known of the genes involved in the regulation of epithelial cell apoptosis) also change progressively as the tissue passes through the consecutive stages of normal mucosa, adenoma, and carcinoma. ${ }^{17}{ }^{19-21}$

These findings suggest that loss of the physiological equilibrium between proliferation and apoptosis in the crypt epithelium occurs in the very early phases of colon carcinogenesis. Whether these changes in the kinetic pattern of human colonic crypts are present in the whole colonic mucosa of subjects at a high risk of cancer development, as a sort of "full field defect", ${ }^{22}$ or whether they are more pronounced in some sites of the colon rather than others is poorly understood. Using an in vitro ${ }^{3} \mathrm{H}$ thymidine labelling technique, Terpstra and colleagues $^{23}$ found that in patients with small adenomas, cell proliferation rates in the proxi-

Abbreviations used in this paper: $\mathrm{ACF}$, aberrant crypt foci; AI, apoptotic index; APC, adenomatous polyposis coli; BrdU, bromodeoxyuridine; BSA, bovine serum albumin; DAB, diaminobenzidine; dUTP, deoxyuridine triphosphate; HNPCC, hereditary non-polyposis colorectal cancer; LI, labelling index; PBS, phosphate buffered saline; PEG, polyethylene glycol solution; TdT, terminal deoxynucleotidyl transferase; TLI, total labelling index; TUNEL, TdT mediated dUTP-biotin nick end labelling. 
mal colon were slightly higher than those of the distal segments. In contrast, there were no significant site related differences in patients with large adenomas or cancer, or in healthy controls. These authors concluded therefore that mucosal biopsy specimens taken from one area of the colon could safely be considered representative of the colon as a whole. However, Ponz de Leon and colleagues, ${ }^{6}$ using the same ex vivo technique, found lower proliferation rates in the caecum compared with other segments in endoscopically normal individuals whose personal and familial histories were negative for colorectal neoplasms, but their report did not provide comparative data on segmental variations in subjects at high risk of colon cancer. Studies by Kubben and colleagues ${ }^{24}$ based on proliferating cell nuclear antigen or bromodeoxyuridine (BrdU) immunohistochemistry found progressively decreasing proliferation indexes moving from right to left along the colorectum in subjects without organic disorders of the colon. In another study, in which cell proliferation was evaluated in healthy humans using crypt cell production rate, the cell turnover rate in the caecum was found to be higher than that of any other site in the colon. ${ }^{25}$ Recently, Liu and colleagues ${ }^{26}$ examined cell proliferation patterns using the Mib-1 antibody to Ki-67 antigen and apoptosis by means of terminal deoxyuridine nucleotidyl nick end labelling (TUNEL) of DNA strand breaks and immunohistochemistry (polyclonal antisera) for Bak, a Bcl-2 homologue that colocalises with sites of epithelial cell apoptosis ${ }^{27}$ throughout the entire length of the normal human colon. Although they found no segment related differences in cell proliferation, the number of epithelial cells undergoing Bak mediated apoptosis in the right colon was lower than that of the left colon or rectum.

In the present study, we assessed cell proliferation and apoptosis in the apparently normal mucosa of different segments of the colon in a group of patients with a history of large sporadic adenomas. The aim of the study was to determine if loss of the equilibrium between these two biological phenomena could be detected throughout the colonic mucosa, representing a generalised phenotypic change that occurs early in the carcinogenetic cascade.

\section{Methods}

STUDY DESIGN

The study was approved by the ethics committee of the Catholic University Medical School of Rome. Informed written consent for all study procedures was obtained from study participants.

The high risk study population was originally composed of 18 patients who had undergone endoscopic polypectomy for removal of one or more sporadic colorectal adenomas $\geqslant 1.5 \mathrm{~cm}$ in diameter. After polypectomy, they had been enrolled in a surveillance programme for patients with colonic adenomas run by three major hospitals in Rome (the medical and surgical departments of the Catholic University and the endoscopy units of the Nuovo Regina Margherita and San Gi- acomo Hospitals). The surveillance protocol provided for pancolonoscopy 6-12 months after polypectomy to confirm the absence of new polyps (clean colon colonoscopy). Recruitment for the present study was limited to patients with large adenomas in an attempt to obtain a population with a homogeneous level of proven risk. ${ }^{28}{ }^{29}$ Exclusion criteria included a family history suggestive of familial adenomatous polyposis or hereditary non-polyposis colorectal cancer (HNPCC), inflammatory bowel disease, previous colorectal surgery, current metabolic or life threatening diseases, clotting defects, and/or pregnancy.

A control group of 13 subjects aged more than 45 years was selected from the population referred to the centres cited above for screening colonoscopy for prevention of colon cancer. Exclusion criteria for the control subjects included all of those for the high risk population as well as the absence of clinical and familial risk factors for colon cancer.

In an attempt to minimise differences in the intake of specific components that might be expected to influence cell kinetics in the colon crypts, all 31 subjects were placed on a standard diet providing a mean caloric intake of $2200 \mathrm{kcal} /$ day, 20 days prior to the study. At the end of this period, dietary adherence was confirmed based on an evaluation of food diaries, and a standard preparation was prescribed consisting of an oral polyethylene glycol solution (PEG 4000; Isocolan-Bracco, Milan, Italy) to be taken in the evening. The solution, which provided a mean overall fluid intake of 3.5-4 litres, contained (per litre) $59 \mathrm{~g}$ of polyethylene glycol, $5.7 \mathrm{~g}$ of sodium sulphate, $1.7 \mathrm{~g}$ of sodium bicarbonate, $1.5 \mathrm{~g}$ of sodium chloride, and $0.7 \mathrm{~g}$ of potassium chloride.

The following morning pancolonoscopy (clean colon colonoscopy) was performed between 0800 and 1200. In the adenoma group, the mean interval between polypectomy and the study examination was nine months. Of the 13 control subjects who were examined during screening colonoscopy, two presented with endoscopic abnormalities and were thus excluded from the remainder of the study.

Using biopsy forceps with a diameter of 2.8 mm (FB 24U-1 Olympus, Tokyo, Japan), we collected a total of 12 samples of flat mucosa from each of the remaining 29 subjects (18 adenoma patients, 11 controls). (The high number of biopsies was necessary to ensure an adequate number of well oriented crypts for the immunohistochemical analysis). The sites of the biopsies were as follows: four from the right colon (from the caecum to the splenic flexure), four from the left colon (from the splenic flexure to the descending sigmoid junction), and four from the rectosigmoid tract (from the descending sigmoid junction to the rectum). Two of the specimens from each site were processed for cell proliferation studies and the other two were used to assess apoptosis. The specimens were carefully positioned on filter paper immediately after biopsy to maintain correct orientation of crypts. 
IMMUNOHISTOCHEMISTRY FOR CELL

PROLIFERATION AND APOPTOSIS

Cell proliferation patterns in the colonic crypts were assessed using BrdU immunohistochemistry. Apoptosis was evaluated using terminal deoxynucleotidyl transferase (TdT) mediated deoxyuridine triphosphate (dUTP) biotin nick end labelling (TUNEL) of DNA strand breaks, as previously described ${ }^{30}$. In brief, for each subject, the following analytical procedures were performed:

\section{Cell proliferation studies}

Immediately after collection, six biopsy specimens of flat mucosa (two from each colon segment) were placed in sterile septum fitted vials containing RPMI 1640 medium supplemented with Hepes-L-glutamine (Gibco, Paisley, Scotland) and 5-bromo-2-deoxyuridine $3 \mathrm{mM}$ (Sigma Chemical Co, St Louis, Missouri, USA). A mixture of $95 \% \mathrm{O}_{2}$ and $5 \% \mathrm{CO}_{2}$ was injected through the septum until the pressure inside the vial was $3 \mathrm{~atm}$. The vials were then incubated at $37^{\circ} \mathrm{C}$ for 90 minutes in a shaking water bath. The specimens were washed with four changes of normal saline solution at $4^{\circ} \mathrm{C}$, fixed in $70 \%$ ethanol overnight, and embedded in paraffin. Immunohistochemical detection of incorporated BrdU was based on the streptavidin-biotin peroxidase complex method (Italscientifica, Genoa, Italy). Tissue sections $(3 \mu \mathrm{m})$ were cleared of paraffin with two changes of xylene and rehydrated in a graded series of ethanol and water. Endogenous peroxidase activity was blocked by immersing the tissue in $3 \% \mathrm{H}_{2} \mathrm{O}_{2}$ in phosphate buffered saline (PBS) ( $\mathrm{pH} \mathrm{7.4)} \mathrm{for} \mathrm{five} \mathrm{minutes}$ at room temperature. DNA denaturation was obtained by adding $2 \mathrm{~N} \mathrm{HCl}$ for 30 minutes at $37^{\circ} \mathrm{C}$. After washing, bovine serum albumin (BSA) $1 \%$ was added to reduce background staining. The sections were incubated for 60 minutes at room temperature with the monoclonal anti-BrdU antibody (Ylem, Avezzano, Italy) diluted 1:100 in PBS. After washing, sections were incubated with streptavidinbiotinylated horseradish peroxidase complex for 45 minutes at room temperature. Finally, diaminobenzidine (DAB) was added for five minutes at room temperature to reveal the immunological reaction. Slides were weakly counterstained with haematoxylin for $10 \mathrm{sec}-$ onds. Slides subjected to the treatment described above with omission of the anti-BrdU antibody were used as negative controls.

\section{Studies of apoptosis}

For each subject, six biopsy specimens of flat mucosa (two from each colon segment) were fixed in $4 \%$ neutral buffered paraformaldehyde overnight at $4^{\circ} \mathrm{C}$ and embedded in paraffin. For in situ detection of apoptotic cells, the TUNEL method described by Gavrieli and colleagues $^{31}$ was used with minor modifications. This technique is capable of detecting cells containing DNA strand breaks. After standard deparaffinisation, sections were digested with $20 \mu \mathrm{g} / \mathrm{ml}$ proteinase $\mathrm{K}$ (Boeringher Mannheim, Germany) for 15 minutes at room temperature. Endogenous peroxidase activity

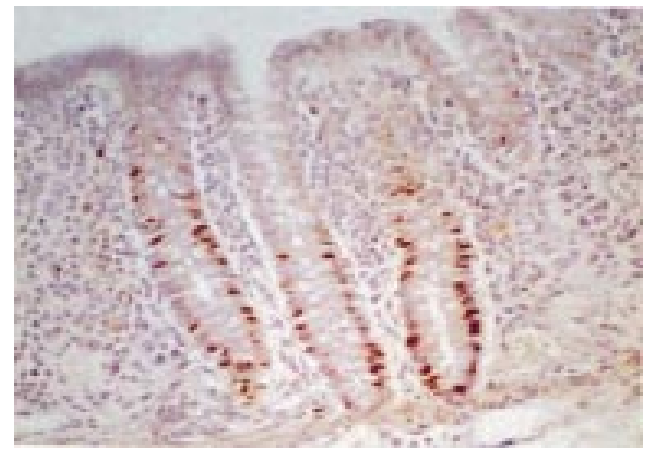

Figure 1 Bromodeoxyuridine immunohistochemistry of human colonic crypts. Brown stained cells (replicating cells) are mostly located at the base of the gland. Original magnification $\times 200$.

was blocked with $\mathrm{H}_{2} \mathrm{O}_{2} 3 \%$ in PBS for five minutes at room temperature. After washing, the slides were placed in the equilibration buffer containing TdT buffer $1 \times, \mathrm{CoCl}_{2} 1 \times$ (Boeringher) for five minutes at room temperature and thereafter in the reaction solution $\left(37^{\circ} \mathrm{C}\right)$ obtained by adding $\mathrm{TdT}$ enzyme $0.3 \mathrm{U} / \mu \mathrm{l}$ and biotin-dUTP $5 \mu \mathrm{M}$ (Boehringer) to the equilibration buffer. The reaction was stopped after 60 minutes. The specimens were washed, and BSA $2 \%$ was applied to reduce background staining. Incorporated biotindUTP was detected after a 45 minute incubation period with streptavidin-horseradish peroxidase complex at room temperature and the $\mathrm{DAB}$ reaction was used to visualise labelled cells. Haematoxylin was applied for 10 seconds to produce weak counterstaining. For each set of slides, histological sections of rat thymus (known to contain numerous apoptotic cells) were run as positive controls. Negative controls consisted of samples of colon mucosa incubated without the TdT enzyme and biotindUTP.

ELIGIBILITY OF SAMPLES AND QUANTIFICATION Our analysis was confined to those crypts whose entire length could be completely visualised. Only well oriented crypts (ideally those whose bases were in contact with the muscularis mucosae) were selected for analysis. Crypts were also excluded from analysis if they violated the $U$ shaped criterion or had multilayered bases. For each subject, a minimum of 20 crypt columns from each area of the colon were examined. All slides were evaluated microscopically by the same examiner (AA) who was unaware of the origin of the specimen (in terms of both group and colon segment).

In the cell proliferation study, BrdU stained cells were identified and counted at $\times 1000$ magnification (fig 1). For each crypt column (hemicrypt), we recorded the total cell number, and the number and positions of labelled cells. The ratio of labelled to total cells was expressed as a percentage and recorded as the total labelling index (TLI) for proliferation. To evaluate the distribution of proliferating cells within the crypt, each column was divided into five compartments from the base (compartment 1) to the mouth of the gland (compartment 5) and a labelling index (LI) 


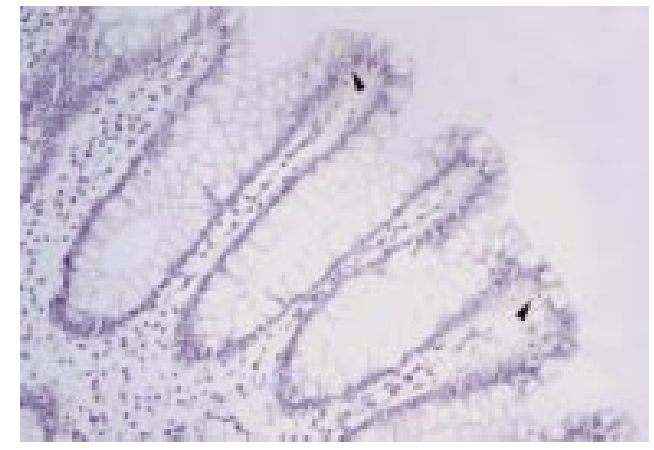

Figure 2 Detection of apoptotoic epithelial cells (arrows) using the TdT mediated dUTP-biotin nick end labelling (TUNEL) method in the upper part of human colonic crypts. Original magnification $\times 200$.

was calculated for each (compartment LI). Because the number of labelled cells in the upper part of the crypt was often quite low, a single LI was calculated for compartments 4 and 5 (compartment $4-5 \mathrm{LI}) .^{34}$

For the study of apoptosis, sections were selected and analysed according to the same criteria used for the cell proliferation studies. TUNEL stained cells were identified along the crypt column and counted at $\times 1000$ magnification. Under normal conditions, apoptotic cells are rare in the glandular epithelium of the colon $^{13}$ and the majority are located in the upper part of the crypts ${ }^{14}{ }^{18}$ (fig 2). For this reason, the LI for apoptosis was calculated only for the crypt as a whole (AI: apoptotic index, that is, the ratio of the number of labelled cells to the total number of cells counted in the column). To minimise errors caused by artefacts, areas of necrosis were excluded from the count of TUNEL labelled cells by comparing each section with an adjacent one stained by haematoxylin-eosin, as described by Moss and colleagues. ${ }^{18}$

For each subject, we calculated mean values for TLI, each of the four compartment LIs, and AI for each of the three colon segments and for the colon as a whole. The latter parameters represented the means for all crypts examined for a given patient. Group means were then calculated for segmental and whole colon indexes.

STATISTICAL ANALYSIS

Data are presented as group means (SEM). Differences between patients and controls were evaluated using the Mann-Whitney U test. The statistical significance of differences between group means was assessed by one way analysis of variance (ANOVA). A p value $<0.05$ was considered significant. When significant differences emerged from ANOVA, post hoc multiple comparisons were made using the Bonferroni test.

\section{Results}

Adherence to the standard diet was considered satisfactory in all subjects in both groups. Three of 18 patients in the adenoma group and two of the remaining 11 control subjects were later excluded from the analysis because an excessively high number of crypts in their histological sections did not meet the criteria
Table 1 Clinical profiles of adenoma patients and controls included in the immunohistochemical analysis

\begin{tabular}{lll}
\hline & Patients & Controls \\
\hline No of subjects & 15 & 9 \\
Sex $(\mathrm{M} / \mathrm{F})$ & $11 / 4$ & $6 / 3$ \\
Age $(\mathrm{y})$ & & \\
$\quad$ Mean & 62.2 & 62.3 \\
$\quad$ Range & $43-72$ & $48-69$ \\
Polyp site & & \\
$\quad$ Right colon & 6 & - \\
$\quad$ Left colon & 8 & - \\
$\quad$ Sigmoid rectum & 5 & - \\
\hline
\end{tabular}

*Total number of polyps removed (four patients had multiple adenomas).

outlined above. Complete data (that is, TLI, compartment LIs, and AI for all three colon segments) were analysed for 15 adenoma patients and nine controls. The profiles of both groups are shown in table 1 .

\section{PROLIFERATION STUDIES}

Data from cell proliferation studies are shown in table 2. Mean length of the crypts (expressed as number of cells per crypt column) did not vary significantly for any colon segment in either of the two groups, and no significant intergroup differences were observed for any given segment (polyp group $v$ controls: 54.1 (2.5) $v 55.8$ (1.7) in the right colon; 57.1 (2.1) $v 55.6$ (1.8) in the left colon; 53.1 (1.9) $v 58.3$ (2.01) in the sigmoid rectum).

Mean whole colon TLI of the adenoma group (8.2 (0.3)) was significantly higher than that of the control group (5.3 (0.2); $\mathrm{p}<0.0001)$. The same was true of the whole colon LIs for compartments 1, 2, 3, and 4-5. All adenoma patients had whole colon TLIs $>7.0$, while corresponding values for each of the controls were $<7.0$ (data not shown). Mean TLIs for each of the three colon segments were also significantly higher in the adenoma group, which accounted for the marked differences between the two groups in the colon as a whole.

In contrast, analysis of the distribution of proliferating cells within the crypts themselves revealed a statistically significant difference between the two groups only for the left colon. Compared with controls, the adenoma group had significantly higher left colon LIs for compartment 1 (17.7 (1.3) v $11.8(0.4), \mathrm{p}<0.01)$, compartment 2 (20.5 (1.1) v. 8.1 (1.7); $\mathrm{p}<0.005)$, compartment 3 (6.9 (1.5) v $0.0(0)$; $\mathrm{p}<0.001)$, and compartments 4-5 (0.9 (0.3) v $0.0(0) ; \mathrm{p}<0.01)$.

There was no significant segmental variation in the TLIs of either group. Segmental analysis of compartmental LIs revealed significant differences for compartment 3 in both groups. In the polyp group, the right colon LI for this compartment was higher than those of both the left colon $(\mathrm{p}=\mathrm{ns})$ and rectosigmoid segment $(p<0.05)$, but only the latter difference was significant. In the control group, the compartment $3 \mathrm{LI}$ for the right colon was significantly higher than those of both the left colon $(p<0.05)$ and rectosigmoid segment $(p<0.05)$. In this case, however, the more distal region showed significantly more compartment 3 proliferation than the left colon $(\mathrm{p}<0.05)$. LIs for the other compartments were essentially the 
Table 2 Whole colon and segmental indexes of epithelial cell proliferation in adenoma patients $(n=15)$ and in controls $(n=9)$

\begin{tabular}{|c|c|c|c|c|c|c|c|c|}
\hline \multirow[b]{2}{*}{ Labelling index } & \multicolumn{4}{|l|}{ Patients } & \multicolumn{4}{|l|}{ Controls } \\
\hline & Whole colon & Right colon & Left colon & $S-R$ & Whole colon & Right colon & Left colon & $S-R$ \\
\hline Total labelling index (TLI) & $8.2(0.3)^{\mathrm{a}}$ & $8.6(0.9)^{\mathrm{b}}$ & $9.2(0.3)^{\mathrm{c}}$ & $7.1(0.4)^{\mathrm{d}}$ & $5.3(0.2)$ & $5.6(0.2)$ & $4.5(0.4)$ & $5.8(0.5)$ \\
\hline \multicolumn{9}{|l|}{ Crypt compartment LI } \\
\hline Compartment 1 & $17.2(1.1)^{\mathrm{e}}$ & $17.7(1.2)$ & $17.7(1.3)^{\mathrm{f}}$ & $16.4(2.7)$ & $12.2(0.7)$ & $11.4(2.2)$ & $11.8(0.4)$ & $13.4(0.9)$ \\
\hline Compartment 2 & $15.9(1.4)^{\mathrm{g}}$ & $15.3(3.0)$ & $20.5(1.1)^{\mathrm{h}}$ & $12.6(2.3)$ & $9.3(0.6)$ & $8.2(0.4)$ & $8.1(1.7)$ & $11.5(0.1)$ \\
\hline Compartment 3 & $6.5(0.7)^{\mathrm{i}}$ & $9.6(1.1)^{\star}$ & $6.9(1.5)^{1}$ & $3.5(0.6)$ & $3.8(0.7)$ & $7.8(0.5) \dagger$ & $0.0(0.0)$ & $3.5(0.1) \ddagger$ \\
\hline Compartments $4-5$ & $0.6(0.1)^{\mathrm{m}}$ & $0.3(0.1)$ & $0.9(0.3)^{\mathrm{n}}$ & $0.5(0.2)$ & $0.05(0.03)$ & $0.0(0.0)$ & $0.0(0.0)$ & $0.1(0.09)$ \\
\hline
\end{tabular}

Whole colon, mean of LIs for crypts in all three segments; S-R, sigmoid rectum.

Results expressed as mean (SEM).

${ }^{a} \mathrm{p}<0.0001 v$ TLI of whole colon of controls; ${ }^{b} \mathrm{p}<0.05 v$ TLI of right colon of controls; ${ }^{\mathrm{p}} \mathrm{p}>0.005 v$ TLI of left colon of controls; ${ }^{\mathrm{d}} \mathrm{p}>0.05 v$ TLI of S-R of controls; ${ }^{e} \mathrm{p}<0.005 v$ compartment 1 LI of whole colon of controls; ${ }^{\mathrm{f}} \mathrm{p}<0.01 v$ compartment 1 LI of left colon of controls; ${ }^{\mathrm{g}} \mathrm{p}<0.05 v$ compartment 2 LI of whole colon of controls; ${ }^{\mathrm{h}} \mathrm{p}<0.005 v$ compartment $2 \mathrm{LI}$ of left colon of controls; ${ }^{\mathrm{i}} \mathrm{p}<0.05 v$ compartment 3 LI of whole colon of controls; ' $\mathrm{p}<0.001 v$ compartment $3 \mathrm{LI}$ of left colon of controls; ${ }^{\mathrm{m}} \mathrm{p}<0.005 v$ compartments $4-5 \mathrm{LI}$ of whole colon of controls; ${ }^{\mathrm{n}} \mathrm{p}<0.01 v$ compartments $4-5 \mathrm{LI}$ of left colon of controls (Mann-Whitney U test).

${ }^{\star} \mathrm{p}<0.05 v$ compartment $3 \mathrm{LI}$ of S-R of patients; $\dagger \mathrm{p}<0.05 v$ compartment $3 \mathrm{LI}$ of left colon and S-R of controls; $\neq \mathrm{p}<0.05 v$ compartment 3 LI of left colon of controls (Bonferroni test after one way ANOVA).

same throughout the entire length of the colon in both groups.

\section{APOPTOSIS STUDIES}

In both the adenoma and control groups, TUNEL positive cells were mostly detected in the upper part of crypts near the border of surface epithelium. This pattern was observed in all segments of the colon.

Mean whole colon AI was significantly lower in the adenoma group than in the control group (1.4 (0.1) v $2.7(0.2) ; \mathrm{p}<0.0001)$. When segmental indexes were compared within each group (fig 3), no differences were found among the control group values (right colon $2.6(0.2)$; left colon $2.7(0.3)$; rectum $2.9(0.5))$ whereas the adenoma group had significantly lower AIs for both the left colon and sigmoid rectum with respect to those of the right colon (left colon $v$ right colon $1.2(0.1)$ v $2.1(0.2)(\mathrm{p}<0.05)$; sigmoid rectum $v$ right colon $1.03(0.1) v 2.1$ $(0.2)(p<0.05))$. Furthermore, indexes for the left colon and sigmoid rectum of the adenoma group were both significantly lower than the

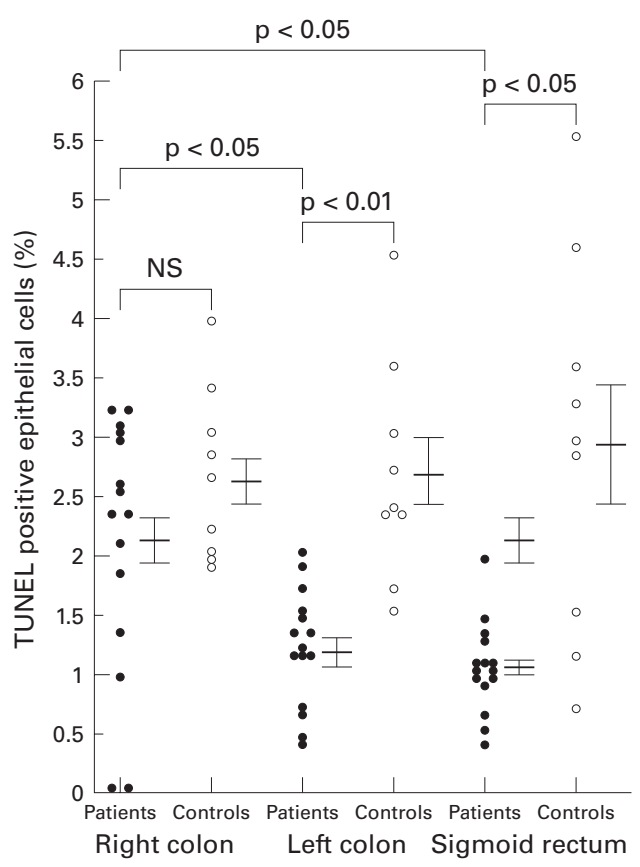

Figure 3 Distribution of apoptotic indexes in three segments of the colon in adenoma patients and controls. Horizontal bars indicate group means (SEM). corresponding segmental indexes for the control group (left colon $1.2(0.1)$ v $2.7(0.3)$ $(\mathrm{p}<0.01)$; sigmoid rectum $1.03(0.1)$ v 2.9 $(0.5)(\mathrm{p}<0.05))$.

\section{Discussion}

In this study, we compared epithelial cell proliferation patterns and apoptosis of patients with (that is, previously resected large adenomas) and without known risk factors for colon cancer. Mucosal biopsies were collected from three segments of the colon to determine the local or diffuse nature of any alterations that might be observed.

Ex vivo BrdU immunohistochemical detection of $S$ phase cells, a standard technique for cell proliferation studies in humans, ${ }^{73}$ revealed a generalised state of hyperproliferation in the high risk group (with respect to that of the controls). Hyperproliferation was manifest as significantly higher whole colon TLIs and an abnormally high number of labelled cells in the upper compartments ( 3 and 4-5) of the crypts. The latter change was primarily responsible for the statistically significant intergroup differences observed in the whole colon LIs for all compartments. These findings confirm previous reports. ${ }^{23} 34$

Conflicting reports have been published on the normal patterns of proliferation (that is, those observed in patients with no known risk factors for colon cancer) in various segments of the colon. ${ }^{62425}$ The discrepancies probably reflect the different techniques used in cell proliferation studies as well as the genetic backgrounds and dietary habits of the subjects examined. For example, even short term variations in the ratio of polyunsaturated/saturated fats in the diet can modify the epithelial kinetic pattern of the colon. ${ }^{32}$ The prestudy diet prescribed for our subjects should have minimised effects of this type.

There was no significant segmental variation in the TLIs within either of our study groups. These observations are consistent with those of Roncucci and colleagues. ${ }^{34}$ Terpstra and colleagues ${ }^{23}$ found intraregional differences in the TLIs of patients with adenomas $<1 \mathrm{~cm}$ but not in those with a history of large adenomas $(>1$ $\mathrm{cm})$. Green and colleagues ${ }^{35}$ reported a significant linear trend across the colon with the highest TLIs in the ascending colon and the lowest in the rectum in patients at $50 \%$ risk of 
carrying mutations for HNPCC. These findings suggest that different colon cancer risk factors (for example, small or large adenoma, familial predisposition) may be associated with different cell proliferation patterns in the colonic mucosa. If so, studies in high risk populations that are heterogeneous in this respect would be expected to produce ambiguous results, and this may explain some of the discrepancies in previously published data. For this reason, we selected patients whose high risk status was based on their history of large adenomatous polyps and excluded those with family histories of colon cancer that might reflect hereditary syndromes.

In the control group, the mean compartment $3 \mathrm{LI}$ for right colon specimens was significantly higher than those of the left colon and sigmoid rectum; a similar difference was noted in the adenoma group. The cause of this regional difference is not clear but may be a result of the specific intraluminal microenvironment of this segment of the colon (microflora, concentration, quality of bile acids, etc). The significance of proliferation within crypt compartment 3 is a matter of some controversy ${ }^{6435}$ but we and other investigators ${ }^{634}$ feel that this finding represents an expansion of the "normal" proliferative compartment at the base of the crypt (compartments 1 and 2). Even if this expansion does not extend to the mouth of the crypt (compartments 4-5), the non-differentiated cells in this intermediate compartment are probably more exposed to various intraluminal factors than those situated in compartments 1 and 2.

Our findings indicate that the normal segment to segment pattern of proliferation is basically preserved in patients with large adenomas, although the rates of proliferation themselves are markedly higher than those found in average risk subjects. There is also a distinctive alteration in the distribution of proliferating cells within the crypts, which is particularly marked in the left colon, and this change implies an additional risk for mutational events because highly vulnerable nondifferentiated cells at the mouth of the crypts are more exposed to intraluminal factors.

The study of apoptosis throughout the colon in these two groups produced interesting results. In control subjects, we found no significant variations in $\mathrm{AI}$ from one segment to another. This finding contrasts with those recently reported by Liu and colleagues ${ }^{26}$ who found fewer TUNEL positive (apoptotic) cells in the right colon than in the left colon or rectum in average risk subjects. The cause of this discrepancy is unclear. These authors have also reported a strong correlation between the percentage of TUNEL positive cells and expression of Bak, a proapoptotic protein that is considered the principal endogenous promoter of programmed cell death in the intestinal epithelium. ${ }^{27}$ In our opinion, this correlation adds credence to their findings. The fact that we did not observe any segmental variations in our control group may, therefore, be a result of the small number of subjects included in this group.
However, data on the adenoma group in our study deserve particular attention. AIs for the left colon and rectosigmoid segment were markedly reduced with respect to those of the right colon, and they were also significantly lower than corresponding values in controls. A number of studies in both animals and humans have indicated that misregulation of the apoptotic activity within colonic crypts plays an important role in colon carcinogenesis. ${ }^{17} 18212236-38$ We have demonstrated that in the high risk population we examined, this misregulation (manifested by decreased rates of apoptosis) is a diffuse phenomenon that involves the apparently normal mucosa of the left side of the colon.

The above mentioned changes in cell turnover of epithelial crypts raise the question of whether these features are an expression of a true phenotypic alteration occurring early in the multistage process of colon carcinogenesis or if they represent an unspecific response to a variety of luminal factors. In the model proposed by Fearon and Vogelstein, ${ }^{2}$ a state of hyperproliferation is thought to precede neoplastic initiation but this concept has recently been questioned..$^{35}$ Some investigators maintain that such changes are a non-specific finding reflecting the influence of factors such as diet, drugs, age, or methodological flaws. In support of this, Green and colleagues ${ }^{35}$ have shown that there is no increase in the somatic mutation rate in the normal mucosa of patients with HNPCC. ${ }^{40}$ However, increased stem cell somatic mutation in the non-neoplastic colorectal mucosa has been described in both familial adenomatous polyposis and Crohn's disease.$^{41}$ In the latter disease, accumulation of somatic mutations has been attributed to the increased regenerative epithelial proliferation associated with inflammatory changes in the colon $^{4041}$ and/or treatment with known mutagens (for example, azathioprine), ${ }^{40}$ and it is believed by some to be linked to the increased risk of development of colon cancer in these patients. ${ }^{40}$ Again, these discrepancies suggest that different risk factors (genetic and acquired) are associated with different levels of risk for mutation in non-neoplastic colonic mucosa. In this context, it seems possible that the generalised alterations in proliferation found in our adenoma patients might increase the probability of mutation in colonic mucosal cells.

The reduced apoptosis we found in the left colon of adenoma patients would further impair the homeostatic equilibrium of epithelial cell renewal in this region, and it might also increase the genetic instability of the mucosa. Garewal and colleagues $^{42}$ found that bile acid induced apoptosis in the normal appearing rectal mucosa of cancer patients was reduced compared with that observed in normal controls and in patients with small polyps. They hypothesised that persistent exposure to carcinogens during the course of a lifetime might lead to a progressive clearance of cells with efficient apoptotic mechanisms with survival selection and accumulation of apoptosis resistant clones that would provide a field 
for cancer development. Interestingly enough, reductions in apoptosis of the same magnitude were also found in three non-cancer patients with different high risk conditions (adenomatous changes in grossly normal appearing mucosa, family history of colorectal cancer, and history of large tubulovillous adenomas).

It is unclear why apoptosis was markedly reduced only in the left colon of our adenoma patients. This and other segmental differences we observed seem to support the hypothesis that environmental factors play a major role in altering glandular epithelial turnover in these patients. In animal models, Western style diets with relatively high fat contents induce a transient but diffuse activation of apoptosis, which is followed by marked depletion of apoptotic cells in the mid region of the colonic crypts and expansion of an epithelial cell population containing atypical nuclei. Mice maintained on these diets for long periods developed single crypt dysplastic lesions. ${ }^{36}$ Regardless of the exact mechanism(s) underlying the changes in the life-death sequence of epithelial crypt cells along the colonic mucosa in patients with a history of large adenomas, the impact of these changes in terms of carcinogenesis is likely to be related to their persistence.

Another interesting point is the relationship between changes in colonic epithelial cell kinetics and aberrant crypt foci (ACF), which are thought to be the microscopic precursors of both polyps and cancer. ${ }^{43-47}$ In colorectal cancer patients, hundreds and hundreds of ACFs have been observed in the normal appearing mucosa of all segments of the colon. ${ }^{45} 48$ Only a few of these foci actually give rise to adenomas or carcinomas: the majority never reach macroscopic dimensions and many even regress. ${ }^{49}$ None the less, their widespread distribution illustrates that in patients with colorectal cancer, the normal appearing mucosa of the entire colon presents morphological changes with the potential to progress towards more advanced stages in the carcinogenetic pathway.

Mutations involving the APC gene are considered to be one of the earliest events in colorectal cancer development. ${ }^{15051}$ This gene is believed to exert one of its main functions by inhibiting cell growth and modulating epithelial cell apoptosis. ${ }^{38}$ However, while APC somatic mutations may be responsible for progression of an ACF to adenoma, they do not appear to be involved in the transformation of normal mucosa to ACF. ${ }^{39} 4952$ Other molecular and biological events must therefore be the cause of ACF development.

Epithelial cell dynamics are profoundly altered in $\mathrm{ACF}^{53-56}$ In rats fed cholic acid, epithelial cells within the azoxymethane induced ACF were shown to be resistant to apoptosis, and the number of cells in the crypts themselves was higher than normal, especially in the middle segment $(+25-40 \%))^{57}$ The importance of this imbalance in cell renewal in ACF has also emerged from experiments on chemoprevention of chemically induced carcinogenesis. Various putative chemopreventive agents have been shown to exert their protective effects by decreasing cell proliferation, enhancing apoptosis, and reducing ACF density ${ }^{58-61}$ Interestingly, in patients with colorectal cancer, there appears to be an increase in the density of ACFs from the right to the left colon, ${ }^{45} 4862$ which parallels the general right to left trend we observed in altered crypt cell turnover in our adenoma patients. This similarity raises the possibility of a relationship (causal?) between loss of equilibrium between cell proliferation and apoptosis rates and the development of ACFs.

The fact that an extensive tract of mucosa was found to harbour glands with a high proliferative propensity and reduced apoptotic activity, as we observed in our study, supports the "field cancerisation hypothesis", 22 according to which longstanding exposure of the mucosa to carcinogens leads to diffuse biological abnormalities throughout large tracts of the colon, which can eventually produce cancers. It is also noteworthy that the severe imbalance between cell proliferation and apoptosis that characterised our high risk group was localised in the left colon where most colon malignancies develop. $^{63} 64$

A number of investigators have found that the normal distribution of apoptotic cells is reversed in adenomatous tissues ${ }^{36} 3765$ which are characterised by an abnormally high density of these cells at the base of the crypts. In our study, the TUNEL positive cells were prevalent at the upper part of the crypt near the surface epithelium in both adenoma controls and patients. This observation suggests that the normal apoptotic cell migration pattern is preserved in the apparently healthy mucosa of high risk patients in spite of the profoundly altered equilibrium between cell proliferation and apoptosis.

The use of in situ end labelling techniques to detect apoptotic cells in the gut and apoptotic indexes for measuring this phenomenon has been criticised by some authors ${ }^{66}$ who believe that this approach does not adequately discriminate between necrotic and apoptotic cells. ${ }^{67-69}$ However, when necrosis can be reasonably excluded, TUNEL positivity is thought to be generally indicative of cells undergoing or about to undergo apoptosis, ${ }^{6769}$ and its sensitivity in detecting apoptotic cells in the human colonic mucosa has been confirmed by several groups. ${ }^{18} 2665$

In conclusion, our findings indicate that epithelial cell kinetics are fairly uniform throughout the entire length of the colon in both low risk subjects and patients with previously resected colon adenomas. However, compared with the former group, high risk patients present higher proliferative rates in all segments of the colon and, in the left colon, marked alterations of the normal distribution of replicating cells within the crypts. In these patients, the left colon is also characterised by clearly reduced apoptosis with respect to that of the right colon for the same group and the entire colon for the control group. These findings indicate that diffuse alteration of cell proliferation and apoptosis occur along the colon as a generalised abnormality in subjects at risk of colon cancer, especially in the left part where 
the profound imbalance between proliferation and programmed cell death may account for the high prevalence of malignancies in this area.

The authors thank Alessandro Rinelli for technical assistance and Marian Kent for help in translating and editing the manuscript. This study was partially supported by a grant from Consiglio Nazionale delle Ricerche (CNR) No 96.02998.CT04, 1996. Preliminary results of this study were presented at the 97th Annual Meeting of the American Gastroenterological Association, Washington DC, 1997.

1 Vogelstein B, Fearon ER, Hamilton SR, et al. Genetic alterations during colorectal tumor development. $N$ Engl f Med 1988;319:525-32.

2 Fearon ER, Vogelstein B. A genetic model of colorectal tumorigenesis. Cell 1990;61:759-67.

3 Lipkin M. Biomarkers of increased susceptibility to gastrointestinal cancer: new application to studies of cancer prevention in human subjects. Cancer Res 1988;48:235-45.

4 Lipkin M, Enker WE, Winawer SJ. Tritiated-thymidine labeling of rectal epithelial cells in "non-prep" biopsies of individuals at increased risk for colonic neoplasia. Cancer Lett 1997;37:153-61.

5 Deschner EE, Lipkin M, Solomon C. Study of human rectal epithelial cells in vitro. II. ${ }^{3} \mathrm{H}$ thymidine incorporation into polyps and adjacent mucosa. F Natl Cancer Inst 1966;36: $849-57$.

6 Ponz de Leon M, Roncucci L, Di Donato P, et al. Pattern of epithelial cell proliferation in colorectal mucosa of normal subjects and of patients with adenomatous polyps or cancer of the large bowel. Cancer Res 1988;48:4121-6.

7 Risio M, Coverlizza S, Ferrari A, et al. Immunohistochemical study of epithelial cell proliferation in hyperplastic polyps, adenomas and adenocarcinomas of the large bowel. Gastroenterology 1988;94:899-906.

8 Anti M, Marra G, Armelao F, et al. Rectal epithelial cell proliferation patterns as predictors of adenomatous colorectal polyp recurrence. Gut 1993;34:525-30.

9 Arends MJ, Wyllie AH. Apoptosis: mechanisms and roles in pathology. Int Rev Exp Pathol 1991;32:223-54.

10 Wyllie AH. Apoptosis. Br f Cancer 1993;67:205-8.

11 Williams GT, Smith CA. Molecular regulation of apoptosis: genetic controls on cell death. Cell 1993;74:777-9.

12 Kerr JF, Wyllie AH, Currie AR. Apoptosis: a basic biological phenomenon with wide-ranging implications in tissue cal phenomenon with wide-ranging im
kinetics. Br f Cancer 1972;26:239-57.

13 Que FG, Gores GJ. Cell death by apoptosis: basic concepts and disease relevance for the gastroenterologist. Gastroen terology 1996;110:1238-43.

14 Hall PA, Coates PJ, Ansari B, et al. Regulation of cell number in the mammalian gastrointestinal tract: the importance of apoptosis. F Cell Sci 1994;107:3569-77.

15 Thompson CB. Apoptosis in the pathogenesis and treatment of disease. Science 1995;267:1456-62.

16 Bedi A, Pasricha PJ, Akhtar AJ, et al. Inhibition of apoptosis during development of colorectal cancer. Cancer Res 1995; 55:1811-16.

17 Baretton GB, Diebold J, Christoforis G, et al. Apoptosis and immunohistochemical bcl-2 expression in colorectal adenomas and carcinomas. Aspects of carcinogenesis and enomas and carcinomas. Aspects of carcinoge

18 Moss SF, Scholes JV, Holt PR. Abnormalities of epithelial apoptosis in multistep colorectal neoplasia demonstrated by terminal deoxyuridine nick end labeling. Dig Dis $\mathrm{Sc}$ 1996;41:2238-47.

19 Hague A, Moorghen M, Hicks D, et al. Bcl-2 expression in human colorectal adenomas and carcinomas. Oncogene 1994;9:3367-70

20 Sinicrope FA, Ruan SB, Cleary KR, et al. Bcl-2 and p53 oncoprotein expression during colorectal tumorigenesis. Cancer Res 1995;55:237-41.

21 Krajewska M, Moss SF, Krajeweski S, et al. Elevated expression of Bcl-X and reduced Bak in primary colorectal adenocarcinomas. Cancer Res 1996;56:2422-7.

22 Slaughter DP, Southwick HW, Smeikal W. Field cancerization in oral stratified squamous epithelium: clinical implication of multicentric origin. Cancer 1953;5:963-8.

23 Terpstra OT, van Blankenstein M. Dees J, et al. Abnormal pattern of cell proliferation in the entire colonic mucosa of patients with colon adenoma or cancer. Gastroenterology
1987;92:704-8.

24 Kubben FJ, Peeters-Haesevoets A, Engels LG, et al. Proliferating cell nuclear antigen (PCNA): a new marker to study human colonic cell proliferation. Gut 1994;35:530-5.

25 Hall C, Youngs D, Keighley MR. Crypt cell production rates at various sites around the colon in Wistar rats and humans. Gut 1992;33:1528-31.

26 Liu LU, Holt PR, Krivosheyev V, et al. Human right and left colon differ in epithelial cell apoptosis and in expression of Bak, a pro-apoptotic Bcl-2 homologue. Gut 1999;45:4550.

27 Moss SF, Agarwal B, Arber N, et al. Increased intestinal Bak expression results in apoptosis. Biochem Biophys Res Comm 1996;223:199-203.

28 Winawer SJ, Zauber AG, O'Brien MJ, et al. Randomized comparison of surveillance intervals after colonoscopic Med 1993;328:901-6.
29 Winawer SJ. Appropriate intervals for surveillance. Gastrointest Endosc 1999;49:S63-6.

30 Anti M, Armuzzi A, Iascone E, et al. Epithelial-cell apoptois and proliferation in Helicobacter pylori-related chron gastritis. Ital f Gastroenterol Hepatol 1998;30:153-9.

31 Gavrieli Y, Sherman Y, Ben-Sasson SA. Identification of programmed cell death in situ via specific labeling of nuclear DNA fragmentation. F Cell Biol 1992;119:493501 .

32 Anti M, Armelao F, Marra G, et al. Effects of different doses of fish oil on rectal cell proliferation in patients with sporadic

33 Boulton RA, Hodgson HJ. Assessing cell proliferation: a methodological review. Clin Sci 1995;88:119-30.

34 Roncucci L, Scalmati A, Ponz de Leon M. Pattern of cell kinetics in colorectal mucosa of patients with different types of adenomatous polyps of the large bowel. Cancer 1991;68:873-8.

35 Green SE, Chapman P, Burt AD, et al. Colonic epithelial cell proliferation in hereditary non-polyposis colorectal cancer. Gut 1998;43:85-92.

36 Risio M, Lipkin M, Newmark H, et al. Apoptosis, cell replication, and Western-style diet-induced tumorigenesis in mouse colon. Cancer Res 1996;56:4910-16.

37 Arai T, Kino I. Role of apoptosis in modulation of the growth of human colorectal tubular and villous adenomas. $\mathcal{F}$ Pathol 1995;176:37-44

38 Morin PJ, Vogelstein B, Kinzler KW. Apoptosis and APC in colorectal tumorigenesis. Proc Natl Acad Sci USA 1996;93: $7950-4$.

39 Jass JR. Colorectal adenoma progression and genetic changes: is there a link? Ann Med 1995;27:301-6.

40 Williams GT, Geraghty JM, Campbell F, et al. Normal colonic mucosa in hereditary non-polyposis colorectal cancer shows no generalized increase in somatic mutation. $\mathrm{Br}$ Cancer 1995;71:1077-80.

41 Campbell F, Geraghty JM, Appleton MAC, et al. Increased stem cell somatic mutation in the non-neoplastic colorectal mucosa of patients with familial adenomatous polyposis. Hum Pathol 1998:29:1531-5.

42 Garewal H, Bernstein H, Bernstein C, et al. Reduced bile acid-induced apoptosis in "normal" colorectal mucosa: a potential biological marker for cancer risk. Cancer Res 1996;56:1480-3

43 Carson DA, Ribeiro JM. Apoptosis and disease. Lancet 1993;341:1251-4.

44 Mc Lellan EA, Bird RP. Aberrant crypts: potential preneoplastic lesions in the murine colon. Cancer Res 1988;48: 6187-92.

45 Roncucci L, Medline A, Bruce WR. Classification of aberrant crypt foci and microadenomas in human colon. Cancer Epidemiol Biomarkers Prev 1991;1:57-60.

46 Pretlow TP, Barrow BJ, Ashton WS, et al. Aberrant crypts: putative neoplastic foci in human colonic mucosa. Cancer Res 1991;51:1564-7.

47 Bird RP, Good CK. The significance of aberrant crypt foci in understanding the pathogenesis of colon cancer. Toxicol Lett 2000;112-113:395-402.

48 Roncucci L, Modica S, Pedroni M, et al. Aberrant crypt foci in patients with colorectal cancer. Br f Cancer 1998;77: 2343-8

49 Smith AJ, Stern HS, Penner M, et al. Somatic APC and K-ras codon 12 mutations in aberrant crypt foci from human colons. Cancer Res 1994;54:5527-30.

50 Powell S, Zilz N, Beazer-Barclay Y, et al. APC mutations occur early during colorectal tumorigenesis. Nature 1992; 359:235-7.

51 Ichii S, Horii A, Nakatsuru S, et al. Inactivation of both APC alleles in an early stage of colon adenomas in a patient with fomilial adenomatous polyposis (FAP). Hum Mol Genet 1992;1:387-90

52 De Filippo C, Caderni G, Bazzicalupo M, et al. Mutations of the APC gene in experimental carcinogenesis induced by azoxymethane in F344 rats. Br f Cancer 1998;77:2148-51.

53 Roncucci L, Pedroni M, Fante R, et al. Cell kinetic evaluation of human colonic aberrant crypts (Colorectal Cancer Study Group of the University of Modena, the Health Care District 16, Modena, Italy). Cancer Res 1993;53:3726-9.

54 Yamashita N, Minamoto T, Onda M, Ensumi H. Increased cell proliferation of azoxymethane induced aberrant crypt foci of rat colon. Ұpn 7 Cancer 1994;85:692-8.

55 Shiptz B, Bonstein Y, Mekori Y, et al. Proliferating cell nuclear antigen as a marker of cell kinetics in aberrant crypt foci, hyperplastic polyps, adenomas, and adenocarcinomas of the human colon. Am 7 Surg 1997;174:425-30.

56 Roncucci L, Pedroni M, Vaccina F, et al. Aberrant crypt foci in colorectal carcinogenesis. Cell and crypt dynamics. Cell

57 Magnusson BA, Shirtliff N, Bird RP. Resistance of aberrant crypt foci to apoptosis induced by azoxymethane in rats chronically fed cholic acid. Carcinogenesis 1994;15:145962.

58 Schmelz EM, Sullards MC, Dillhay DL, et al. Colonic cell proliferation and aberrant crypt foci formation inhibited by dairy glycosphingolipids in 1,2-dimethylydrazine treated CF1 mice. F Nutr 2000;130:522-7.

59 Smith TK, Lund EK, Johnson IT. Inhibition of dimethylhydrazine-induced aberrant crypt foci by induction of apoptosis in rat colon following oral administration of the glucosinolate singrin. Carcinogenesis 1998;19:26773

60 Lathan P, Lund EK, Johson IT. Dietary n-3 PUFA increases the apoptotic response to 1,2 -dimethylhydrazine, reduces 
mitosis and suppresses the induced carcinogenesis in the rat colon. Carcinogenesis 1999;20:645-50

61 Agarwal B, Rao CV, Bhendwal S, et al. L sulindac-induced apoptosis in colon cancer cells and potentiates chemopreventive effects of sulindac. Gastroen terology 1999;117:838-47.

62 Yamashita N, Minamoto T, Ochiai A, et al. Frequent and characteristic K-ras activation and absence of $\mathrm{p} 53$ protein accumulation in aberrant crypt foci of the colon. Gastroenterology 1995;108:434-40.

63 Morson BC. Evolution of cancer of the colon and rectum. Cancer 1974;34(suppl):845-9.

64 Shinya H, Wolff WI. Morphology, anatomic distribution and cancer potential of colonic polyps. Ann Surg 1979;190: 679-83.
65 Moss SF, Liu TC, Petrotos A, et al. Inward growth of colonic adenomatous polyps. Gastroenterology 1996;111: 1425-32.

66 Potten CS. What is an apoptotic index measuring? A commentary. Br f Cancer. 1996;74:1743-8.

67 Kressel M, Groscurth P. Distinction of apoptotic and necrotic cell death by in situ labelling of fragmented DNA. Cell Tissue Res 1994;278:549-56.

68 Grasl-Kraupp B, Ruttkay-Nedecky B, Koudelka H, et al. In situ detection of fragmented DNA (TUNEL assay) fails to discriminate among apoptosis, necrosis and autolytic cell death: a cautionary note. Hepatology 1995;21:1465-8.

69 Coates PJ. Molecular methods for the identification of apoptosis in tissues. F Histotechnol 1994;17:261-7. 